\title{
Carbon recycling via carbonate dissolution in subduction zones: Perspectives from molybdenum and boron isotopes
}

\author{
YUNYING ZHANG ${ }^{1}$, Min SUN ${ }^{1}$, CHAO YUAN ${ }^{2}, \mathrm{JIE} \mathrm{LI}^{2}$ \\ 1 Department of Earth Sciences, The University of Hong \\ Kong, Pokfulam Road, Hong Kong, China \\ (zyy518@hku.hk) \\ ${ }^{2}$ State Key Laboratory of Isotope Geochemistry, Guangzhou \\ Institute of Geochemistry, Chinese Academy of Sciences, \\ Guangzhou 510640, China
}

Subduction zones are critical sites for carbon cycling between Earth's surface and interior, which modulate the global carbon budget and influence Earth's climate. However, how subducted carbon is released and transferred to the surface is not well understood, especially regarding the role of slab-derived fluids in the deep carbon cycle. Here we investigate the Mo and $\mathrm{B}$ isotopic compositions for the Silurian normal arc andesites from the Chinese Tianshan, which represent products of fluid-modified mantle wedge. The normal arc andesites yield remarkably higher $\delta^{98} \mathrm{Mo}$ values $(0.33-1.08 \%$ ) than that (about $-0.20 \%$ ) of the depleted mantle. Because their limited range of $\mathrm{SiO}_{2}(53.8-$ 55.3 wt.\%) precludes differentiation as a cause for their variable $\delta^{98}$ Mo values and Mo isotopic fractionation solely by fluid mobilization is limited $(\leq 0.3 \%)$, such elevated $\delta^{98} \mathrm{Mo}$ values could be ascribed to the incorporation of crustal materials with heavy Mo isotope in the mantle source. Since marine carbonate is characterized by both heavy Mo and B isotopes and our normal arc andesites also show relatively heavy $\delta^{11} \mathrm{~B}(-1.63$ to $+4.00 \%)$ values, we consider that marine carbonate was possibly involved as a component of the subducted slab, which modified the Mo-B isotopic compositions of the mantle source. The positive correlations between $\delta^{98} \mathrm{Mo}$ and $\delta^{11} \mathrm{~B}$ and between $\delta^{98} \mathrm{Mo}$ and $\mathrm{Ba} / \mathrm{Rb}$ imply transport of subducted carbonates to the overlying mantle wedge via slab fluids, thus providing robust evidence for transfer of subducted carbon to the overriding plate by carbonate dissolution.

Acknowledgement: This work was financially supported by the National Science Foundation of China (41603030, 41973021) and the Hong Kong RGC research projects (17303415, 17302317). 